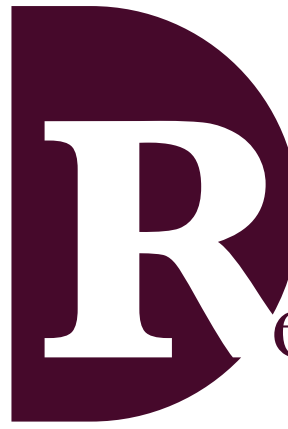

ISSN 1992-6510

Año 20, N 52, San Salvador, El Salvador, Centroamérica. Revista Semestral Julio-Diciembre 2020

YEAR 20, N52, SAN SALVADOR, EL SALVADOR, CENTRAL AMERICA. SEMESTRAL JOURNAL JULY-DECEMBER 2020

\title{
Modelo de evaluación del desarrollo urbano en el Área Metropolitana de San Salvador
}

\section{Evaluation model for the San Salvador Metropolitan Area Urban development}

Carlos M. Carcache Carlos M. Carcache

Arquitecto, Universidad Politécnica de El Salvador Maestría en Artes, University of South Carolina Diplomado en desarrollo urbano sostenible de las Universidades de Delft y Wageningen, Holanda. Diplomado en Pintura Europea: Leonardo, Rembrandt, Goya de la Universidad Carlos III de Madrid, España. Diplomado en Tecnología Educativa de la Universidad Politécnica de Valencia, España. Docente investigador a tiempo completo, Universidad Francisco Gavidia ccarcache@ufg.edu.sv

Fecha de recibido: 16 de noviembre de 2019 Fecha de aprobación: 17 de diciembre de 2019 DOI: 10.5377/ryr.v52i52.10642 


\section{RESUMEN}

Este proyecto de investigación pretende establecer una forma de medir (un modelo) el grado de sostenibilidad del desarrollo urbano en el Área Metropolitana de San Salvador y es un esfuerzo que se suma al de otras entidades pensando en ¿cómo se puede modificar nuestra infraestructura actual para suplir las necesidades del AMSS sin comprometer la seguridad y prosperidad de las generaciones futuras? La investigación se enmarca exclusivamente dentro de la porción geográfica del AMSS e incluye la revisión de algunos modelos que se han aplicado con éxito en algunas ciudades de España para tenerlos como un referente a la hora de diseñar e implementar el propio.

Se espera que este sistema de observación del desarrollo urbano local, en su primera fase, pueda servir de base para la creación de un laboratorio urbano en el cual se produzcan cifras propias que lleven a resultados precisos y de esa manera propiciar o estimular la elaboración de futuros estudios en el campo de la sostenibilidad, y más aún, que nuevas generaciones de estudiosos del urbanismo logren dotar de inteligencia urbana suficiente al AMSS para que ésta sea considerada una ciudad sostenible.

Palabras clave: Sostenibilidad, desarrollo urbano, AMSS, indicadores, ciudades sostenibles.

\section{ABSTRACT}

This research project aims to establish a way to measure (a model) the degree of sustainability of urban development in the Metropolitan Area of San Salvador, hereinafter AMSS, and is an effort that adds to that of other entities thinking about how you can modify our current infrastructure to meet the needs of the AMSS without compromising the security and prosperity of future generations?

The research is framed exclusively within the geographical portion of the AMSS and includes the review of some models that have been successfully applied in some cities in Spain to have them as a reference when designing and implementing their own.

It is hoped that this system of observation of local urban development, in its first phase, can serve as a basis for the creation of an urban laboratory in which own figures are produced that lead to precise results and thus propitiate or stimulate the development of future studies in the field of sustainability, and even more so that new generations of urban planning scholars will be able to provide AMSS with sufficient urban intelligence so that it is considered a sustainable city.

Keywords: Sustainability, urban development, AMSS, indicators, sustainable cities. 


\section{Introducción}

¿Tiene el Área Metropolitana de San Salvador (en adelante AMSS) una oportunidad real de alcanzar un desarrollo urbano sostenible...? La anterior es una interrogante que preocupa a muchos ciudadanos del AMSS y es una pretensión de este documento que el lector considere esta frase como una invitación a reflexionar sobre cómo aunar esfuerzos con las Entidades Estatales y estudiosos del desarrollo urbano para hacer de San Salvador una ciudad inteligente, ambientalmente sana, limpia y segura, en la que todas las personas y sus familias encuentren condiciones dignas para trabajar, convivir y obtener los recursos adecuados para prosperar.

Este documento es también una invitación al lector para unirse al esfuerzo de corregir el daño ambiental causado al AMSS y al resto del país por:

- Excesiva emisión de gases de vehículos y motos en mal estado.

- Mala utilización y desperdicio de recursos naturales.

- Ausencia de cultura automovilística.

- Mal manejo de desechos.

- Mal uso y deterioro de la infraestructura pública.

Antes de pretender emitir un juicio crítico sobre la situación actual y la calidad de vida de los ciudadanos del AMSS es pertinente formular algunas preguntas cuyas respuestas no pueden darse en forma categórica, más aun, las respuestas a algunas de esas preguntas pueden ser tan inciertas que resulta aventurado dar un pronóstico categórico y son ellas precisamente las que han motivado el desarrollo de esta investigación.
- ¿Estamos creciendo o decreciendo?

- ¿Hacia dónde vamos?

- ¿Qué queremos ser?

- ¿Vamos realmente en la dirección que queremos?

- ¿Con qué herramientas tecnológicas, ecológicas y sociales contamos para diseñar, controlar y orientar el desarrollo del AMSS hacia un futuro ideal?

- ¿Qué soluciones metropolitanas necesitan ser implementadas en el AMSS para lograr un cambio hacia el desarrollo?

- ¿Cómo crear un AMSS más próspera para todos los ciudadanos?

- ¿Cuáles pueden ser las consecuencias de la urbanización no controlada en el AMSS?

- ¿Cómo puede el AMSS volverse un área sustentable y próspera?

La inteligencia urbana es un tema esencial en el desarrollo urbanístico de las ciudades, obviamente la planificación e implementación de estos sistemas competen al Estado, principalmente, pero también es responsabilidad de la empresa privada y de todos los ciudadanos. Alcanzar la sostenibilidad del desarrollo urbano en una metrópoli no depende de la voluntad de unos pocos sino de todos los ciudadanos que viven en ella.

Una de las pretensiones de este estudio es perfilar el grado de sostenibilidad del desarrollo urbano del Área Metropolitana de San Salvador mediante la estructuración de un modelo basado en la evaluación de objetivos estratégicos e indicadores propios del desarrollo urbano y de esa manera contribuir a encontrar soluciones que mitiguen algunos de los complejos desafíos que enfrenta el AMSS. 
Otra de las pretensiones del proyecto es tratar de dar alguna respuesta a las preguntas del prefacio en fases futuras.

Todas las ciudades del mundo son potencialmente inteligentes, unas más que otras, lograrlo al 100\% es un reto difícil de alcanzar que no depende sólo de la voluntad del Estado sino también de la disponibilidad de recursos adecuados. En el caso del AMSS, durante los últimos 20 años, las entidades estatales y de asocio público privado han dado pasos importantes en esa dirección y este proyecto se une a ese esfuerzo.

Debido a que la situación del desarrollo urbano descrita en el prefacio de este documento es sólo una aspiración de los habitantes del AMSS, y ya que todas las preguntas incluidas en el mismo inciso se las hace más de alguna vez la mayoría de los ciudadanos, es que nace la intención de perfilar el grado de sostenibilidad del AMSS que incluye varios sistemas urbanísticos y para ello se recurre a la revisión de diferentes técnicas y/o sistemas de medición aplicados exitosamente en distintas ciudades europeas.

Como memoria de investigación y para lograr el cumplimiento de objetivos se determinarán algunos factores estadísticos básicos del AMSS, se identificarán diversas clases de objetivos estratégicos e indicadores que oportunamente serán analizados y tabulados hasta estructurar un modelo de desarrollo urbano que permitirá perfilar de manera aproximada el grado de sostenibilidad del desarrollo urbano en el AMSS hasta el año 2018.

Es importante mencionar que existen casos de gobiernos en América del Sur que tomaron la determinación de suplir la demanda nacional de vivienda de interés social habilitando líneas de crédito especiales para adquisición de vivienda al grado de llegar a construir alrededor de 3 millones de unidades habitacionales, efectivamente, la intención era sana: resolver el problema de las familias desposeídas que no tenían casa, y aquí viene lo importante de esta reflexión, la solución de este problema propició la aparición de otro igual de grande, las familias pobres que antes no tenían techo, hoy tienen casa pero ya no las quieren y protestan debido a la mala calidad de las construcciones de interés social. Moraleja, es hora de alejarse de la mediocridad y empezar a hacer las cosas con profesionalismo y buena calidad...

La reflexión anterior es una alerta para que los municipios participen activamente en el proceso de desarrollo urbano de sus localidades y tengan presente que no se trata simplemente de invertir un mínimo en unidades habitacionales para resolver el problema de la falta de techo, se trata de crear un entorno digno donde las familias puedan desarrollarse de manera integral, de crear comunidades sanas, con espacios habitables y de esparcimiento adecuados. Sin importar el estrato social, los sectores residenciales pueden sufrir deterioro por diversos factores y el AMSS crece descontroladamente en diversas direcciones y este crecimiento no es ocasionado por la simple y pura expansión vial..., hay toda una serie de razones por las cuales muchas familias residentes de las colonias Escalón y San Benito emigraron a la periferia de Santa Tecla, a los municipios de Antiguo Cuscatlán y Nuevo Cuscatlán, y hacia otros municipios ubicados sobre la carretera hacia el puerto de La Libertad, en otras palabras hacia la 
periferia del AMSS, lo lamentable es que la infraestructura del AMSS no está preparada para incorporar estos nuevos desarrollos y las consecuencias las sufre el medioambiente.

Es por ello que una de las expectativas más grandes de este proyecto de investigación es que el modelo de desarrollo se convierta en la base de una plataforma a partir de la cual se pueda profundizar en el estudio de los diferentes microentornos urbanos del AMSS; otra expectativa es que este documento estimule a futuros estudiosos del tema a aplicar metodologías experimentales distintas que lleven a resultados más profundos o tal vez a encontrar nuevas formas de estudiar o analizar los problemas urbanísticos del AMSS; y finalmente, la posibilidad de poder efectuar desde la Universidad Francisco Gavidia (en adelante UFG), un monitoreo periódico y permanente de los diversos sistemas urbanos del AMSS.

\section{Objetivos}

- Perfilar el grado de sostenibilidad del desarrollo urbano en el AMSS.

- Identificar objetivos e indicadores en modelos existentes de desarrollo urbano españoles que sean aplicables en el AMSS.

- Formular un modelo piloto de evaluación del desarrollo urbano que permita medir el grado de sostenibilidad alcanzado en el AMSS sentando las bases para la creación de un Laboratorio Urbano Institucional.

- Estructurar este proyecto de investigación para ser desarrollado por etapas.
- Perfilar, en una primera fase, el grado de sostenibilidad del desarrollo urbano en el AMSS basado principalmente en datos oficiales publicados durante el último quinquenio (2013-2018).

- La metodología incluirá un sistema de antecedentes con referentes de enfoque local y global.

\section{El AMSS, situación actual}

Circular diariamente por el AMSS da, a veces, la impresión de que en términos de desarrollo urbano nuestra ciudad se encamina irremediablemente a una situación que podría calificarse de insostenible. Las consecuencias físicas y emocionales que ocasiona el desarrollo no controlado en los ciudadanos del AMSS son graves y de diversas clases y a medida que transcurre el tiempo se agudizan más. Los grados de intolerancia observados en los automovilistas locales se manifiestan en violencia y agresión sin importar el estrato social al que estos pertenezcan, la cultura automovilística de los conductores del transporte público y de otras clases de transporte pesado es lamentable. Los niveles de inseguridad en algunas comunidades, calles y buses sobrepasan los límites de la racionalidad y a todo esto se suman los problemas de desorden, contaminación, suciedad e invasión de ventas en las calles. La contaminación por emisión de gases tóxicos del transporte público y de otros tipos de vehículo como motocicletas, carros viejos, camiones o pick ups es deplorable. E1 proyecto identifica algunos sistemas urbanísticos del AMSS que tienen un funcionamiento inadecuado afectando la vida diaria de los ciudadanos, los más evidentes son: 


\section{Tabla 1}

Variables con funcionamiento inadecuado en el AMSS

\begin{tabular}{c|l}
\hline \multicolumn{1}{|c}{ Sistemas con funcionamiento inadecuado en el AMSS } \\
\hline 1 & Patrimonio cultural desatendido \\
\hline 2 & Vías urbanas estrechas y con capacidad sobrepasada \\
\hline 3 & Alto grado de contaminación por mal manejo de desechos \\
\hline 4 & Contaminación visual de calles \\
\hline 5 & Contaminación auditiva \\
\hline 7 & Emisión desmedida de gases tóxicos: polución vehicular, polución industrial, quemas agrícolas \\
\hline 8 & Mobiliario urbano inadecuado o inexistente \\
\hline 9 & Transporte público mal planificado, inseguro e insuficiente \\
\hline 10 & Mantenimiento de calles \\
\hline 11 & Presencia mínima de cultura ciudadana \\
\hline 12 & Infraestructura educativa deficiente \\
\hline 13 & Infraestructura de salud deficiente \\
\hline 14 & Presencia mínima de cultura automovilística \\
\hline 15 & Quebradas con emisión permanente de malos olores por drenaje de aguas negras \\
\hline 16 & Usos de suelo inapropiados \\
\hline
\end{tabular}

Fuente: Elaboración propia.

Como ya se mencionó, esta investigación se inicia con una reflexión: ¿Tiene el Área MetropolitanadeSan Salvador una oportunidad real de alcanzar un desarrollo urbano sostenible...? Esta interrogante surge en la mente de muchos ciudadanos al experimentar las consecuencias de un desarrollo urbano con problemas de control, administrativos, logísticos, etc., incluso algunas personas son categóricas haciendo afirmaciones, como la de un locutor de una emisora local en el mes de febrero de 2019, al que oía en mi carro en medio del congestionamiento típico del bulevar Los Próceres durante las horas pico de la mañana: “...el tráfico en San Salvador ya no tiene remedio...” A la larga, esta frase -medio en serio y medio en broma- es también una hipótesis descriptiva, es una afirmación concluyente sobre la situación que se vive a diario en la mayoría de las calles del AMSS durante las horas pico.

\section{Los cuatro pilares del desarrollo sostenible}

San Salvador es una ciudad que en algún momento en el tiempo tuvo un desarrollo urbano planificado y ordenado, hoy en día, el urbanismo local requiere una atención bastante más especializada para que los ciudadanos del AMSS, que pueden ser acreditados con un nivel de resiliencia sorprendente, se desarrollen en forma integral y puedan legar a las futuras 
generaciones una ciudad digna. Por lo tanto, algunas razones adicionales que justifican el estudio de esta problemática son las siguientes:

- Es un tema oportuno, más bien urgente..., claro y preciso.

- El estudio está enfocado hacia una problemática teórico-práctica identificable en los diversos sistemas urbanos que conforman la ciudad de San Salvador y municipios aledaños ya que es el área de mayor concentración poblacional en el país.

- El proyecto llena un vacío de investigación a nivel institucional en la UFG en la rama del urbanismo.

- Finalmente, es lamentable observar cómo un porcentaje grande de la población tiene formación escolar básica pero su nivel de educación, de cultura y civismo son paupérrimos. Esta última condición de la idiosincrasia del habitante del AMSS no debe ignorarse a la hora de planificar una sostenibilidad permanente y progresiva. En la introducción de este documento se mencionan algunas variables relacionadas con el nivel de educación y cultura del capitalino por lo que puede afirmarse que uno de los obstáculos más grandes para alcanzar la sostenibilidad en el AMSS es la falta de educación de sus ciudadanos.

En esta fase inicial del proyecto es importante dejar claro que el grado de seriedad con que otras naciones se esmeran en mantener y cultivar el campo cultural queda de manifiesto en la siguiente declaración:
El Bureau Ejecutivo de Ciudades y Gobiernos Locales Unidos, a partir de la extensa labor desempeñada por la Comisión de Cultura de CGLU, así como de la Declaración Universal sobre la Diversidad Cultural de UNESCO en 2001 y la Convención sobre la Diversidad de las Expresiones Culturales de UNESCO en 2005, se acordó en Chicago en abril de 2010, dar el mandato a la Comisión de Cultura para elaborar el documento de orientación política sobre la cultura como cuarto pilar del desarrollo sostenible. (CGLU, 2010: 3)

Según (CGLU, 2010: 6) se enuncian los 4 pilares del desarrollo sostenible:

1. E1 crecimiento económico.

2. La inclusión social.

3. El equilibrio medioambiental.

4. La cultura.

\section{Referencias históricas}

Las referencias históricas en este proyecto están orientadas a la determinación de lo que ya se hizo en otras metrópolis para lograr un desarrollo urbano sostenible, de tal manera que este documento inicia revisando la participación de algunas entidades estatales responsables del desarrollo urbano. Las referencias históricas se incluyen con dos enfoques: local y global, estas últimas serán útiles a la hora de determinar en qué situación nos encontramos con relación al resto del mundo.

En E1 Salvador, a lo largo de los siglos XX y XXI se han creado entidades como el Ministerio de Gobernación y Desarrollo Territorial, OPAMSS, MOP, MARN, FONAES, el Viceministerio 
de Transporte y otros, los cuales han dado pasos importantes encaminados a planificar $y$ controlar el desarrollo de los diferentes sistemas urbanos que configuran el AMSS dando como resultado una urbe tal y como la conocemos hoy. El esfuerzo en planificación, normatividad y construcción de infraestructura de las partes responsables de solucionar los problemas del desarrollo urbano sostenible en el AMSS no ha tenido los resultados esperados, un ejemplo de estos "esfuerzos" es PLAMATRANS cuyas proyecciones para 2017 eran tener un tráfico controlado durante las horas pico y calles ampliadas en diferentes sectores de la ciudad.

E1 Área Metropolitana de San Salvador es una urbe de catorce municipios, de los cuales doce pertenecen al departamento de San Salvador y dos al departamento de La Libertad, ubicada en la zona central del país. De acuerdo a databank (2016), la población del AMSS asciende a $\mathbf{2 , 1 7 7 , 4 3 2}$ habitantes distribuidos en $611 \mathrm{~km}^{2}$ que representan el $27.5 \%$ de la población total del país y según Datosmacro (2017) equivalentes al 3\% del territorio nacional.

- El AMSS posee una densidad de 3,563 hab./ $\mathrm{km}^{2}$ (databank, 2016)

- El área urbanizada del AMSS es de 175.28 $\mathrm{km}^{2}$ y genera una densidad de $\mathbf{1 2 , 4 4 2}$ hab./ $\mathrm{km}^{2}$. (databank, 2016)

Uno de los factores que afecta el desarrollo urbano del AMSS es la densidad habitacional, la cual a su vez es consecuencia del alto costo de la tierra edificable, donde un ejemplo claro de esta situación es Cuscatancingo, con una densidad de 13,769 hab./km² (EHPM, 2017: 4).
Las urbanizaciones de interés social responden a una serie de normas y porcentajes preestablecidos por entidades estatales, "estándares mínimos" que en la mayoría de los casos propician que los diseñadores y constructores lleven las “soluciones" habitacionales y urbanísticas a condiciones que buscan maximizar la rentabilidad de sus inversiones a costa de la dignidad de las personas. Lamentablemente esta práctica ha generado que las áreas residenciales, entre otras cosas, no cuenten con áreas verdes idóneas sino mínimas.

Por otra parte, la configuración arquitectónica de las urbanizaciones se ve rápidamente transformada por las necesidades y costumbres de sus habitantes y este problema se agudiza cuando los residentes deben desplazarse para suplir necesidades esenciales como el trabajo, el comercio, la educación, la salud o el ocio y para establecer esta conexión es imprescindible la construcción de vías de circulación "adecuadas", las cuales recién construidas cumplen con las normas, pero con la ocupación de las urbanizaciones en corto tiempo su capacidad queda sobrepasada.

La planificación de áreas verdes en sectores de alta densidad podría enfocarse de una manera distinta, podrían revisarse los porcentajes mínimos incluidos en la normativa estatal, estos tipos de urbanización deberían contar con porcentajes dignos de área verde de acuerdo a la cantidad de usuarios del proyecto. Las consecuencias de los costos y normativa establecida en los reglamentos de construcción para proyectos de alta densidad son de diversas clases: alto grado de hacinamiento, bajísimos estándares de construcción, insuficiencia de áreas verdes, etc. Estos proyectos, por su misma 
configuración y realidad social, en el corto plazo se vuelven absolutamente antiestéticos y entre otras cosas, propician la inseguridad y la descomposición social.

San Salvador se ha desarrollado urbanísticamente absorbiendo municipios aledaños e incorporando la infraestructura de esos municipios al sistema general de la ciudad y la consecuencia de ese fenómeno ha sido que los recursos planificados y disponibles no sean suficientes para absorber esa demanda de infraestructura y nuevos servicios. El AMSS mantiene una clara dependencia bidireccional con su entorno inmediato y zonas aledañas, existe una relación permanente entre tecnología y personas, naturaleza y cultura, estas relaciones se establecen mediante flujos circulares de energía, agua, productos agrícolas, alimentos, materias primas y toda clase de desechos entrantes y salientes. Esta dependencia o reciprocidad entre el área urbana y el área rural o suburbana puede considerarse dinámica ya que se caracteriza por diferentes escalas de interacción, y por involucrar una mezcla compleja de sistemas técnicos y sociales como los descritos en el párrafo anterior.

Administrativamente, el municipio de San Salvador ha sido dividido en 6 distritos, regidos todos por la Alcaldía de San Salvador. Cada uno de los distritos cuenta con una serie de servicios estatales para gestionar cierta clase de trámites y pagos, algunos de estos distritos son incluidos en la página de la Alcaldía de San Salvador (bttps://alcaldiass.wordpress.com); la necesidad de todos los servicios obliga a sus habitantes a desplazarse por la ciudad y muchas personas lo hacen en transporte público. Ahora bien, algunos investigadores consideran que este desplazamiento es uno de los causales potenciales del congestionamiento de tráfico en las áreas metropolitanas y consideran que este factor podría disminuir si las comunidades contaran en sus distritos con sucursales "completas" de las dependencias prestadoras de servicios para poder realizar sus transacciones y obligaciones tributarias localmente.

\section{Índice de desempeño ambiental: Universidad de Yale}

La Universidad de Yale junto con The Center for International Earth Science Information Network de Columbia University (EPI, 2018) a partir del año 2006 lanzan un programa piloto de medición del desarrollo sostenible en el que se evalúan las tendencias de protección al medio ambiente y se convierte en una herramienta importante para la formulación de políticas ambientales efectivas basadas en datos. El programa se conoce con el nombre de Índice de Desempeño Ambiental, EPI. Este programa, entre otras cosas, se enfoca en la detección de problemas, rastreo de tendencias, destacar los éxitos y fracasos de las políticas, identificación de las mejores prácticas y hace recomendaciones para optimizar los beneficios de las inversiones en gestión ambiental.

El alcance del EPI en 2018 llega a calificar 24 indicadores divididos en 10 categorías y participan 180 países alrededor del mundo entre los cuales se incluye El Salvador que ocupó la posición 106. Las variables utilizadas por la Universidad de Yale para establecer estos índices están alineadas en dos grandes categorías: 1) Salud Ambiental y 2) Vitalidad del Ecosistema, lo cual resulta ilustrativo para el proceso de 
definición de los indicadores que se incluirán en el modelo de la UFG (EPI, 2018):

- Salud ambiental, que aumenta con el crecimiento económico y la prosperidad.

- Vitalidad del ecosistema, que sufre la industrialización y la urbanización. algunos arquitectos que últimamente abogan por transformar la capital en una ciudad compacta; el proyecto CAT-MED se basa precisamente en eso, “...en desarrollar modelos urbanos sostenibles basados en la ciudad clásica mediterránea compacta, compleja y donde la escala peatonal marca la proximidad a los servicios públicos" (CAT-MED, 2016).

\section{Tabla 2}

Yale University. (2018). Índice de desempeño ambiental de El Salvador. Recuperada y parcialmente adaptada de: https://epi.envirocenter.yale.edulepi-topline (fecha de consulta el 28 de marzo de 2019).

\begin{tabular}{|c|c|c|c|c|}
\hline \multicolumn{5}{|c|}{ Environmental performance index - EPI } \\
\hline \multicolumn{5}{|c|}{ Center for Environmental Law \& Policy, Yale University, 2018} \\
\hline Country & ranking & EPI & Environmental health & Ecosystem vitality \\
\hline El Salvador & 106 & 53.9 & 63.99 & 47.19 \\
\hline
\end{tabular}

Como ya se anticipó, El Salvador ocupó la posición 106 entre 180 países, fue calificado con un grado de desarrollo sostenible de 53.91, un grado de salud ambiental de 63.99 y un grado de vitalidad del ecosistema nacional de 47.19, este último indicador evidencia un deterioro alto, progresivo y preocupante de los recursos naturales del país, la tabla también muestra algunos indicadores que oscilan entre 10 y 40 puntos los cuales deben ser considerados como una alerta, por lo que esta evaluación es una justificación más para la elaboración de este documento y para unirlo al esfuerzo de las entidades estatales y privadas que tratan de elevar el grado de sostenibilidad del desarrollo urbano en el AMSS.

\section{Modelo Urbano Sostenible CAT-MED}

Se consideró oportuno revisar este modelo CAT-MED ya que en El Salvador existen
Los arquitectos no debemos ignorar la escala actual del AMSS, y no debemos emitir juicios apresurados sobre soluciones urbanísticas que han funcionado en ciudades no relacionadas con las nuestras, el AMSS ha adquirido unas proporciones y una cohesión tal que requiere de teorías bien estructuradas y basadas en su propia realidad urbana para resolver el problema urbanístico en San Salvador,por lo que no se puede afirmar que "x o y" modelo sea el apropiado. San Salvador nunca ha tenido una base de desarrollo medieval ni características mediterráneas para afirmar que la teoría de la ciudad compacta es el camino correcto al desarrollo urbano y sobre todo, porque no hay ningún proyecto piloto que respalde el argumento de una posible sostenibilidad. El sistema de transporte público es lamentable y todavía el Estado cuenta con sistemas administrativos centralizados. La población en general tiene un nivel cultural que 
urge mejorar, “....si se quiere vivir en ciudades de primer mundo las personas deben comportarse como ciudadanos de primer mundo" (anónimo).

Una ciudad compacta implica un desarrollo integrado donde la organización del espacio urbano determina la movilidad peatonal en todas direcciones; implica también una dinámica circular en la gestión de recursos naturales, energéticos y de servicios para la comunidad; finalmente la urbe intervenida debe responder a las necesidades de sus ciudadanos de alcanzar un desarrollo económico y social dignos, cosas que difícilmente pueden lograrse cuando los cimientos de la sociedad están socavados por la corrupción y la inseguridad. Los indicadores del Modelo Urbano Sostenible del proyecto CAT-MED son 20 y se agrupan sobre 4 ejes principales, a continuación, se incluye una tabla mostrando el modelo.

El objetivo general de CAT-MED es actuar sobre los modelos urbanos de organización territorial, contribuyendo a que la configuración de la ciudad facilite no solo una mayor eficiencia energética, sino que ello suponga el aumento de la movilidad y la accesibilidad entre las personas y la distribución de bienes y servicios, aumentando la accesibilidad y conectividad humana, la cohesión social, que deriva en una mejor calidad de vida para el conjunto de la población. (CAT-MED, 2019)

El proyecto CAT-MED enfocado en la preservación de los recursos naturales y en disminuir las excesivas emisiones de $\mathrm{CO}_{2}$ del tráfico vehicular es particularmente interesante para este estudio porque las alcaldías de estas ciudades españolas junto con las de algunas ciudades de Italia como Turín, Roma y Génova están dispuestas a pasar de la teoría a la acción, ¡y lo están logrando...! CAT-MED tiene unos objetivos claros y lo más importante, tienen la determinación de corregir el daño causado al entorno por la inconciencia de los ciudadanos. Ver Tabla 3.

La conclusión a la que se llega revisando este modelo es que el concepto de gobernabilidad en países europeos lleva implícito un deseo de trabajar por el desarrollo integral de las ciudades y por ende de sus habitantes. Las ciudades con desarrollos autosostenibles son aquellas en las que la extrema pobreza o la miseria han sido erradicadas; la autosostenibilidad precisamente se encarga de que el esfuerzo de las comunidades respaldado por la voluntad del Estado culmine en bienestar para todos. Es posible, pero poco probable, que exista corrupción en el gobierno de los países europeos, y si hay personajes corruptos no son el común denominador de la clase política, el Estado trabaja en busca del bienestar de la comunidad en general y no del interés particular, existe una conciencia social generalizada en relación con la durabilidad de los recursos naturales y las consecuencias que puede tener el despilfarro y mal uso de ellos, lo cual es producto de un nivel de formación y educación altos.

\section{Modelo de desarrollo sostenible EcoDistricts - BID}

Denise Levy, especialista ambiental en la Unidad de Salvaguardias y Melissa Barandiarán, consultora ambiental para el Grupo de Salvaguardias Ambientales (ESG) ambas funcionarias del $\mathrm{BID}$, en relación con el movimiento EcoDistricts afirma que: 


\section{Tabla 3}

Modelo urbano sostenible - Proyecto CAT-MED. (2019). Servicio de Programas Europeos Ayuntamiento de Málaga. Metodología de trabajo y resultados, España. Recuperado y parcialmente modificada de: http:// www.catmed.eu/pag/es/10/el-modelo-urbano (fecha de consulta el 2 de abril de 2019).

\begin{tabular}{l|l|l|l}
\hline $\begin{array}{c}\text { Territorio y configuración } \\
\text { de la ciudad }\end{array}$ & \multicolumn{1}{|c|}{ Movilidad y transporte } & \multicolumn{1}{|c}{$\begin{array}{c}\text { Gestión de los } \\
\text { recursos naturales }\end{array}$} & \multicolumn{1}{c}{$\begin{array}{c}\text { Cohesión socialy } \\
\text { económica }\end{array}$} \\
\hline 1. Densidad de población & 6. Reparto modal del tráfico & 11. Consumo de energía & $\begin{array}{l}\text { 16. Proximidad a servicios } \\
\text { básicos }\end{array}$ \\
\hline 2. Compacidad urbana & $\begin{array}{l}\text { 7. Proximidad a paradas de } \\
\text { transporte público }\end{array}$ & 12. Consumo de agua & $\begin{array}{l}\text { 17. Porcentaje de viviendas } \\
\text { de protección pública }\end{array}$ \\
\hline 3. Complejidad urbana & $\begin{array}{l}\text { 8. Proximidad a la red de } \\
\text { carriles en bicicletas }\end{array}$ & $\begin{array}{l}\text { 13. Gestión y recogida de } \\
\text { residuos }\end{array}$ & $\begin{array}{l}\text { 18. Tasa de población activa } \\
\text { y desempleo }\end{array}$ \\
\hline $\begin{array}{l}\text { 4. Zonas verdes y áreas de } \\
\text { esparcimiento }\end{array}$ & $\begin{array}{l}\text { 9. Porcentaje de calles y } \\
\text { espacios peatonales }\end{array}$ & 14. Calidad del aire & $\begin{array}{l}\text { 19. Evolución de la frecuen- } \\
\text { cia turística }\end{array}$ \\
\hline $\begin{array}{l}\text { 5. Proximidad a zonas verdes } \\
\text { y áreas de esparcimiento }\end{array}$ & 10. Emisiones de $\mathrm{CO}_{2}$ & 15. Calidad del silencio & $\begin{array}{l}\text { 20. Actividades medioam- } \\
\text { bientales en la escuela } \\
\text { primaria }\end{array}$ \\
\hline
\end{tabular}

Medir y evaluar la sostenibilidad urbana puede llegar a ser un desafío, pero es también alentador darse cuenta de que no necesitamos proyectos grandes para comenzar. ¡Podemos pensar en un vecindario a la vez, siempre y cuando inspiremos a otros a unirse al movimiento! (BID, 2019)

\section{Modelo de Cantabria}

La región de Cantabria en España cuenta con un Observatorio de la Sostenibilidad que monitorea el desarrollo urbano de la región mediante una serie de indicadores que han sido considerados por la comunidad especializada como unas herramientas útiles y eficaces que permiten analizar, evaluar y valorar la evolución del progreso hacia el desarrollo sostenible en ciudades intermedias. Según Nogués y Salas (2008: p32) el objetivo fundamental del Observatorio de la Sostenibilidad es aportar una propuesta de reestructuración de la red urbana de
Cantabria para fomentar el equilibrio territorial y mejorar la capacidad de desarrollo de toda la región. Este observatorio se convierte entonces en un proyecto invaluable para las autoridades de esa región ya que gracias al monitoreo de su propio desarrollo buscan alternativas para lograr un equilibrio territorial, y ésta es la razón principal por la que se incluye este modelo dentro de las referencias para este proyecto. En el modelo de Cantabria, las investigadoras afirman que:

El crecimiento disperso de las ciudades tradicionalmente compactas a la larga resulta poco sostenible. Si esto es una constante quiere decir que a mediano o largo plazo el AMSS correrá la misma suerte, será poco sostenible por el tipo de crecimiento que está teniendo, ....el fenómeno de la dispersión urbana trae como consecuencia una modificación del modelo de ocupación del suelo (Nogués y Salas, 2008: 29). 
Lo anterior es algo que empieza a evidenciarse en San Salvador, Antiguo Cuscatlán y Santa Tecla. El modelo también deja claro que la mayoría de las ciudades del mundo han experimentado las consecuencias que trae la concentración excesiva o el hacinamiento y las investigadoras mencionan que el nuevo modelo de sistemas policéntricos es una alternativa que reduce estos efectos.

De acuerdo a la información en Datosmacro. com (2018), Cantabria es una región del norte de España con aproximadamente 581,000 habitantes, y según foro-ciudad.com (2018) su capital Santander tiene alrededor de 172.000 habitantes. Las investigadoras Nogués y Salas (2018: p 30-34) señalan también algunos asentamientos en los que existen núcleos potenciables que podrían llegar a satisfacer las necesidades y servicios requeridos en la región de Cantabria, esta situación de proximidad de las ciudades satélites o periféricas debe aprovecharse para dotar a sus núcleos o centros urbanos de todos los servicios estatales y privados posibles para lograr precisamente la policentricidad de las metrópolis".

Por otra parte, Nogués y Salas (2008: p31) optaron por un sistema de clasificación denominado Índice de Nelson que es útil en estudios de jerarquía urbana y delimitación de áreas de influencia y al aplicar el modelo, las investigadoras concluyeron lo siguiente:

- Existe un desequilibrio en la red urbana de Cantabria por una excesiva dependencia de Santander para funciones básicas.

- Se requiere un sistema descentralizado de Entidades Estatales más equilibrado con núcleos intermedios mejor dotados de proveedores de servicios estatales.

- Deben existir varios de estos nodos localizados en puntos especialmente accesibles de la región, de modo que entre todos cubran la demanda de servicios de frecuencia semanal y algunos esporádicos (salud) y solamente si fuese necesario desplazarse a nodos de mayor rango para funciones especializadas.

- Se requieren nuevas estrategias y políticas para favorecer el equilibrio territorial mediante la ubicación concentrada de población, actividades y servicios a partir de la distribución en nodos de diferente magnitud. (Nogués y Salas, 2008)

La recomendación final de las investigadoras es que la ciudad de Santander debe constituir un modelo policéntrico o polinuclear bien jerarquizado basado en el desarrollo de núcleos compactos, en el que la ciudad de Santander actúe como centro o núcleo principal pero apoyada por una importante red de ciudades y núcleos urbanos interrelacionados entre sí, con el objetivo de paliar la concentración en la capital y evitar la excesiva expansión del desarrollo urbano de baja densidad en su alrededor. Explican además que los sectores de la ciudad que crecen de manera dispersa tienen un desarrollo poco sostenible: "La construcción de vías de gran capacidad junto con el aumento de la motorización y las nuevas pautas de consumo han propiciado que ciudades tradicionalmente compactas hayan experimentado un crecimiento disperso, que a la larga resulta ser poco sostenible. (Nogués y Salas, 2008: 32) 
Aparentemente y de acuerdo a información del Departamento de Geografía, Urbanismo y Ordenación del Territorio de la Universidad de Cantabria, en el caso de esta provincia la mayoría del crecimiento disperso se debe a la expansión vial y entre las razones y consecuencias de la dispersión habitacional uno puede entrever que los beneficiados en cierta medida son los ciudadanos, ya que logran adquirir mejores viviendas (mejor calidad de la infraestructura), a mejores precios (costos razonables y asequibles), en ambientes seguros y limpios (entornos eco-amigables) y más grandes (tamaño de la propiedad), en resumen viviendas dignas.
Nogués y Salas (2008) hacen una descripción muy precisa de los problemas que caracterizan el interior de las ciudades y principalmente el centro urbano: “... problemas de congestión vehicular, suciedad, inseguridad, polución, hacinamiento urbano, etc."

En octubre de 2007, la Red Local de Sostenibilidad de Cantabria estableció una serie de 27 indicadores que medirían a partir de ese momento el desarrollo urbano de esta región, 12 comunes y 15 específicos, incluidos a continuación:

\section{Tabla 4}

Indicadores de sostenibilidad local de Cantabria: Resumen del proceso de elaboración. Fernández, C. (2007). Recuperado y parcialmente modificada de: http://www.medioambientecantabria.es/documentos_ contenidos/21748_5.4.pdfpp.15-17(fecha de consulta el 2 de mayo de 2019).

\begin{tabular}{l|l}
\hline \multicolumn{1}{c|}{ Indicadores comunes } & \multicolumn{1}{c}{ Indicadores específicos } \\
\hline 1. Movilidad local y transporte de pasajeros. & 1. Desplazamiento de los niños entre la casa y la escuela. \\
\hline 2. Existencia de zonas verdes y servicios locales. & 2. Educación en la sostenibilidad (social, económicay ambiental). \\
\hline 3. Utilización sostenible del suelo. & 3. Conservación de la biodiversidad. \\
\hline 4. Consumo de recursos naturales: agua y energía. & 4. Conservación del paisaje. \\
\hline 5. Generación y gestión de residuos. & $\begin{array}{l}\text { 5. Gestión sostenible de la administración local y de las } \\
\text { empresas locales. }\end{array}$ \\
\hline 6. Calidad del aire en el municipio. & 6. Tendencia poblacional. \\
\hline 7. Calidad de las aguas continentales y litorales. & 7. Aguas de abastecimiento y aguas residuales. \\
\hline 8. Bienestar de la población. & 8. Erosión de los suelos. \\
\hline 9. Satisfacción de la ciudadanía con la comunidad local. & 9. Contaminación acústica. \\
\hline 10. Contribución local al cambio climático. & 10. Sostenibilidad del sector forestal. \\
\hline 11. Participación ciudadana. & 11. Sostenibilidad del sector agroganadero. \\
\hline 12. Actividad económica local. & 12. Vivienda y construcción sostenible. \\
\hline & 13. Seguridad ciudadana. \\
\hline & 14. Productos que fomentan la sostenibilidad. \\
\hline & 15. Sostenibilidad del sector turístico. \\
\hline
\end{tabular}


La conclusión a la que se llega estudiando el modelo de estas investigadoras es la existencia de dos problemas principales que se deben resolver en las ciudades pequeñas:

- Una excesiva dependencia de la ciudad grande (Santander) para funciones básicas.

- Una infradotación de los núcleos intermedios.

\section{Modelo de Asturias}

Asturias ha desarrollado una estrategia de desarrollo sostenible en la que se ha definido el Perfil Ambiental de Asturias el cual es un informe, basado en indicadores, sobre el estado del medio ambiente en el Principado de Asturias y desde 2008 el Observatorio de la Sostenibilidad trabaja en la definición de las metodologías para la aplicación de los indicadores de sostenibilidad de esta estrategia.

De acuerdo al Observatorio de la Sostenibilidad de Asturias:

Los 54 indicadores seleccionados para la elaboración de este perfil ambiental se distribuyen en 11 temas: aire y ruido, cambio climático, agua, naturaleza y biodiversidad, suelo, residuos, energía, desastres naturales, agricultura y ganadería, pesca, movilidad y transporte y gestión para la sostenibilidad". Los resultados de la implementación de este modelo se verán en el corto y mediano plazo debido a que el tema del desarrollo sostenible se ha trabajado con otros enfoques y todo ese esfuerzo anterior, como el del Observatorio de la
Sostenibilidad, constituye una base sólida para alcanzar los grados de sostenibilidad ansiados. (Perfil Ambiental de Asturias, 2017: pp. 8-24)

El Sistema de Indicadores de Desarrollo Sostenible del Principado de Asturias ha sido finalmente reestructurado en 53 indicadores agrupados en 6 temas, 33 subtemas y en 2 niveles de información.

\section{Modelo de Barcelona}

E1 desarrollo urbano en Barcelona se encamina hacia la sostenibilidad a pasos agigantados gracias al trabajo del Observatorio Barcelona que de acuerdo a la página de Cámara de Comercio Barcelona (CAMBRABCN.ORG, 2019) el desarrollo de esta ciudad está al nivel de las principales ciudades de Europa y del mundo y lo determina mediante la evaluación de 30 indicadores en diferentes sectores. Incluso en el campo del desarrollo energético Barcelona viene trabajando en una nueva matriz, en la creación de un modelo energético inteligente. A continuación, en la Tabla 5, se anexan los indicadores de este modelo incluidos en el Informe 2016 del Observatorio Barcelona y forman una muy buena base para establecer los indicadores del modelo institucional UFG.

Es importante mencionar que en estos momentos la Universidad de Barcelona trabaja en el diseño y aplicación de objetivos y metas de la Agenda 2030 de la ONU, pero los esfuerzos para alcanzar la sostenibilidad no son nuevos, Barcelona llega al grado de medir en un indicador su posición en el mundo como ciudad innovadora que del año 2015 al 2017 pasó del puesto número 27 al 


\section{Tabla 5}

Indicadores incluidos en el Informe 2016 del Observatorio Barcelona. Recuperado de: https://www. cambrabcn.org/es/que-te-ofrecemos/estudios-economicos-infraestructuras/observatorio-de-barcelona (Fecha de consulta el 9 de mayo de 2019) Parcialmente modificada.

\begin{tabular}{|c|c|}
\hline \multicolumn{2}{|l|}{ Modelo del Observatorio Barcelona } \\
\hline \multirow[t]{2}{*}{ 1. Biodiversidad } & 1,1. superficie verde \\
\hline & 1,2 biodiversidad de aves \\
\hline \multirow[t]{2}{*}{ 2. Espacio público y movilidad } & 2,1. eco movilidad \\
\hline & 2,2 seguridad vial \\
\hline \multirow[t]{3}{*}{ 3. Calidad y salud ambiental } & 3,1. calidad del aire \\
\hline & 3,2. calidad acústica \\
\hline & 3,3. calidad del agua para consumo humano \\
\hline \multirow[t]{3}{*}{ 4. ciudad eficiente, productiva y de cero emisiones } & 4,1. renovación del parque residencial \\
\hline & 4,2. consumo de agua \\
\hline & 4,3. penetración de las TIC en los hogares \\
\hline \multirow[t]{4}{*}{ 5. Uso racional de los recursos } & 5,1. consumo responsable \\
\hline & 5,2. generación de residuos municipales \\
\hline & 5,3. recolección selectiva de residuos \\
\hline & 5,4. destino de los residuos municipales \\
\hline \multirow[t]{3}{*}{ 6. Buena gobernanza y responsabilidad social } & 6,1. gastos municipales en las esferas medioambiental y social \\
\hline & 6,2. deuda del gobierno municipal \\
\hline & 6,3. certificaciones en el ámbito de la sostenibilidad \\
\hline \multirow[t]{6}{*}{ 7. Bienestar de las personas } & 7,1. esperanza de vida al nacer \\
\hline & 7,2. accesibilidad de la vivienda \\
\hline & 7,3. niveles de ocupación \\
\hline & 7,4. distribución de los ingresos \\
\hline & 7,5. acceso a la oferta cultural \\
\hline & 7,6. satisfacción de los ciudadanos \\
\hline 8. Progreso y desarrollo & 8,1. innovación \\
\hline 9. Educación y acción cívica & 9,1. niveles de educación \\
\hline \multirow[t]{2}{*}{ 10. Resiliencia y responsabilidad planetaria } & 10,1. cambio climático \\
\hline & 10,2. autosuficiencia energética \\
\hline
\end{tabular}

número 13. Barcelona tiene una serie de barrios o sectores que han sido recuperados, renovados o desarrollados en forma local, aislada, y de esa manera, poco a poco, han logrado un desarrollo innovador y sostenible para toda la ciudad. Son ejemplo extraordinario, un modelo imitable para todas las ciudades del mundo. 


\section{Smart Cities - Metodología CES-BID}

E1 documento La ruta hacia las Smart Cities: Migrando de una gestión tradicional a la ciudad inteligente resume la metodología del Banco Interamericano de Desarrollo para Ciudades Emergentes Sostenibles:

La primera etapa comienza con la ejecución de una herramienta de diagnóstico de evaluación rápida para identificar los retos de sostenibilidad de una ciudad. Las etapas siguientes incluyen agua, calidad del aire, la transparencia, etc. Son priorizados a través del uso de múltiples filtros - ambiental, económico, opinión pública y experticia de especialistas por sector- para identificar los problemas que plantean los mayores desafíos para la sostenibilidad de una ciudad. Por último, un plan de acción es formulado, conteniendo las intervenciones priorizadas y un conjunto de estrategias para su ejecución a través del corto, mediano y largo plazo. En la segunda etapa, la fase de ejecución se inicia con la preparación de estudios de preinversión para las intervenciones priorizadas $y$ la implementación de un sistema de monitoreo ciudadano. (Bouskela, M., Casseb, M., Bassi, S., De Luca, C. y Facchina, M., 2016: pp. 43-49).

En el Programa de Ciudades Emergentes y Sostenibles del BID se establece una metodología denominada CES que tiene una aplicación directa en países de América Latina y el Caribe:

Las ciudades emergentes de esta región requieren de procesos de desarrollo orientados hacia acciones y propuestas específicas, capaces de catalizar una mejor calidad de vida urbana. La metodología CES promueve la idea de que las estrategias de desarrollo urbano bien planificadas, integrales $y$ multisectoriales tienen la capacidad de brindar mejoras a la calidad de vida y de trazar un futuro más sostenible, resiliente e inclusivo para las ciudades emergentes de América Latina y el Caribe. Más recientemente, el programa ha estado trabajando en el fortalecimiento de la metodología CES incluyendo temas relacionados a desarrollo económico local, competitividad y la creación de empleo productivo. La propuesta de ajuste metodológico establece un nuevo conjunto de 10 temas, 15 subtemas y 17 indicadores. Además, el marco metodológico actualizado recomienda tres nuevos estudios de base adicionales sobre desarrollo económico, añadiendo otros 23 indicadores. Esta actualización facilitará un análisis más robusto de la economía local, permitiendo que la CES identifique de mejor manera estrategias para promover el desarrollo económico sostenible y equitativo a nivel de ciudad. CES está llevando a cabo pruebas piloto para evaluar la robustez y la aplicabilidad de la propuesta en Quetzaltenango, Guatemala y San José, Costa Rica. (IADB.ORG, 2016).

\section{Modelo de sostenibilidad 2030 de la ONU}

A lo largo de los años, la Organización de las Naciones Unidas ha tenido un papel dinámico 
estimulando a los países para alcanzar un desarrollo urbano íntegro y digno a nivel mundial con diversas iniciativas en Europa, Medio Oriente, Asia y Norteamérica. Revisando la información en la página de la ONU relacionada con los Objetivos de Desarrollo Sostenible se encuentra documentado el último esfuerzo de esta organización por alinear a los países del mundo en una cruzada en pro de la autosostenibilidad y la inteligencia urbana en todas las ciudades del mundo, y uno de los párrafos de la resolución incluido a continuación refleja el espíritu y la visión de esta iniciativa:

Estamos resueltos a poner fin a la pobreza y el hambre en todo el mundo de aquí a 2030, a combatir las desigualdades dentro de los países y entre ellos, a construir sociedades pacíficas, justas e inclusivas, a proteger los derechos humanos $\mathrm{y}$ promover la igualdad entre los géneros y el empoderamiento de las mujeres y las niñas, y a garantizar una protección duradera del planeta y sus recursos naturales, señalaron los Estados en la resolución. (UN.ORG, 2015).

Esta reunión histórica en Europa, en la que participaron más de 150 países concluyó con la firma de una resolución a la que llamaron la Agenda 2030 para el Desarrollo Sostenible ha propiciado cambios en las estrategias para medir el grado de sostenibilidad del desarrollo urbano y para ello se han establecido una serie de objetivos estratégicos de desarrollo sostenible, diecisiete (17) para ser exactos y cada uno de ellos contiene una serie de metas (169 indicadores) en los campos económico, social y ambiental (ONU, 2015).
Aunque es una lista larga, los objetivos estratégicos de la ONU y sus metas o indicadores son relevantes para este estudio porque permiten visualizar el grado de profundidad con que los países desarrollados están evaluando la sostenibilidad de su desarrollo urbano.

\section{Sobre los resultados de la evaluación de modelos}

De acuerdo al sistema de Indicadores del Desempeño Ambiental de la Universidad de Yale, El Salvador ocupa la posición 106 a nivel mundial, y que en ese modelo la cantidad de indicadores evaluados son 26, aunque también debe mencionarse que son un grupo de indicadores orientados hacia la medición de partículas en diversos sistemas ambientales.

Al hacer esta relación de 26 a 169 indicadores, es decir, los indicadores de Yale equivalen a la sexta parte de los indicadores en la Agenda 2030 de la ONU pudiéndose apreciar en esta relación la magnitud del esfuerzo y participación de la ONU y la trascendencia de esta Agenda 2030 en el campo del desarrollo urbano sostenible, aunque no por eso el sistema de evaluación de Yale University es menos importante.

\section{Metodología}

La metodología utilizada en este proyecto, en una primera fase, establece un sistema de antecedentes de dos tipos: referencias de enfoque local y referencias de enfoque global. Una vez determinadas las referencias (modelos de desarrollo exitosos) se efectúa una identificación de objetivos estratégicos (metas) e indicadores de sostenibilidad relacionables con la realidad de El Salvador con el objeto de estructurar un 
modelo institucional que pueda ser replicado en cualquier sector del territorio nacional.

Este prototipo de modelo de evaluación del desarrollo urbano de la UFG es estructurado y probado en una fase inicial con cifras provenientes de sitios web oficiales y documentación bibliográfica de los últimos 5 años (20132018) con los cuales se puede perfilar un índice que refleja un grado muy aproximado de la sostenibilidad del desarrollo urbano en el AMSS para el año 2018.

Las fases futuras de la investigación implican materializar el concepto de un Laboratorio Urbano Institucional y consisten en incorporar nuevos indicadores al modelo de evaluación, establecer diferentes y más convenientes formas de medir nuevos indicadores que permitan finalmente hacer modelos de predicción periódicos, anuales o para cada 5 o 10 años, etc.

En diversos medios se considera que la sostenibilidad tiene 3 pilares, pero como ya se determinó anteriormente la cultura es un factor esencial en el desarrollo de los pueblos y constituye por derecho propio el pilar número 4, ignorarlo sería pretender que un pueblo sumido en la barbarie pueda llegar a ser autosostenible y es lógico suponer que en continentes donde la cultura siempre ha estado presente, se la aprecia, se estimula, y por ende, no se la considere como uno de los objetivos estratégicos para el desarrollo urbano, lamentablemente, ese no es ni remotamente el caso de El Salvador, por lo tanto los pilares de la sostenibilidad son 4, incluidos en el Planteamiento y Justificación del Problema en la gráfica 1 de este documento.
Con base en lo anterior, los indicadores del modelo deben garantizar la inclusión de las cuatro categorías (pilares de la sostenibilidad) y al mismo tiempo deben tomarse en consideración los modelos del BID y la clasificación de Objetivos de Desarrollo de la Sostenibilidad (ODS) que hace la ONU en su Agenda 2030 por ser uno de los modelos más completos que se han diseñado.

\section{Configuración del modelo UFG: Selección de indicadores}

El sistema de criterios de selección se organizará de acuerdo a los modelos del BID y de la ONU por considerar que son los modelos más completos y recientes que rigen el concierto mundial en materia de objetivos estratégicos y metas para modelos de desarrollo urbano sostenible. Los problemas que caracterizan el interior de muchas ciudades en América Latina son indicadores que deben preocupar a las autoridades responsables del desarrollo urbano: congestión vehicular, suciedad, inseguridad, polución, hacinamiento urbano, etc., y tratar de dar respuesta a estas situaciones de manera integral de lo contrario la solución de un problema puede provocar otro problema social.

Con base en lo anterior, es particularmente interesante mencionar el fenómeno chileno resultante de aplicar una política de financiamiento para adquisición de vivienda de interés social mediante la cual se han construido y entregado alrededor de 3 millones de casas, cifra que constituye de acuerdo a Rodríguez y Sugranyes (2004, vol. 30, N91, pp. 53-65) el $30 \%$ de la demanda nacional; lo curioso 
del fenómeno es que el gobierno tratando de solucionar el problema de la falta de techo ha generado otro igual de grave. En un principio las personas no tenían techo, no tenían casa, hoy las mismas familias tienen viviendas con techo, ipero las viviendas y las urbanizaciones son de tan mala calidad que ya no quieren vivir en ellas...!

Los indicadores que se incluyen en este modelo de evaluación del desarrollo urbano son los que pueden medirse con viabilidad desde la Universidad Francisco Gavidia teniendo como restricción los recursos disponibles y el tiempo asignado para esta fase.
Como parte de la metodología del proyecto los objetivos estratégicos e indicadores fueron seleccionados a partir de criterios generales, la metodología incluyó una revisión de los diferentes modelos, posteriormente se procedió al análisis de la información recopilada y la conclusión ha sido la estructuración de un modelo de evaluación que incluye un total de 16 indicadores agrupados en 11 objetivos estratégicos que se pueden ver en la Gráfica 1.

Revisando la documentación correspondiente a los diferentes modelos, la matriz inicial para el modelo institucional tendrá una configuración similar a la de la Tabla 6.

\section{Gráfica 1.}

Modelo de evaluación del desarrollo urbano UFG

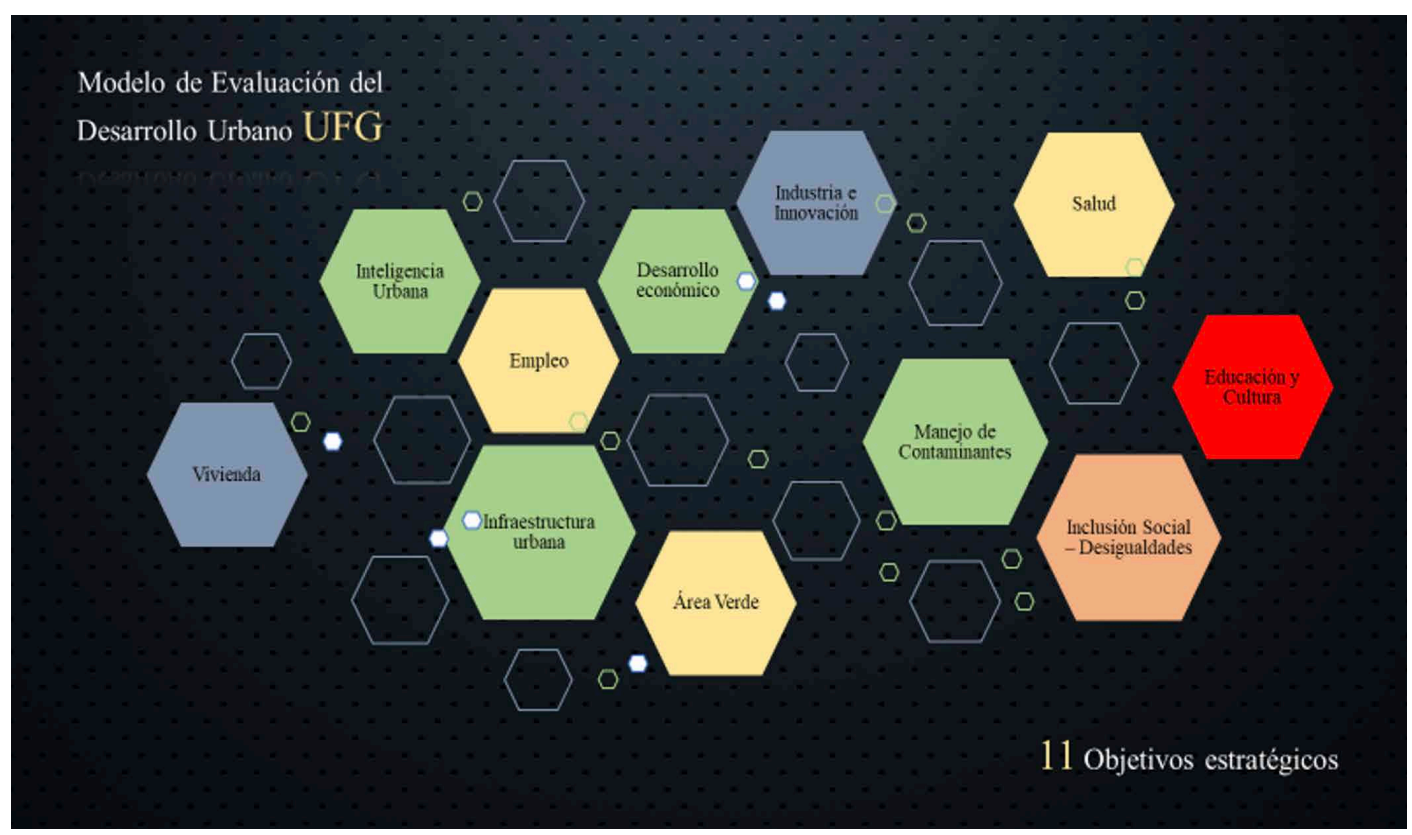

Fuente: elaboración propia. 
Tabla 6

Objetivos estratégicos e indicadores, modelo de evaluación UFG

\begin{tabular}{|c|c|c|}
\hline \multicolumn{3}{|l|}{$\begin{array}{l}\text { Modelo de evaluación UFG } \\
\text { Objetivos estratégicos e indicadores }\end{array}$} \\
\hline Objetivos estratégicos & & Indicadores \\
\hline 1. Vivienda & 1 & Déficit de vivienda \\
\hline 2. Empleo & 2 & Tasa de desempleo de mujeres y hombres de todas las edades \\
\hline 3. Desarrollo económico & 3 & PIB per cápita en relación con el PIB en países desarrollados \\
\hline 4. Inteligencia Urbana & 4 & Servicios del Estado accesibles a través de Internet \\
\hline 5. Industria e innovación & 5 & Número de hogares sin acceso a Internet \\
\hline \multirow{2}{*}{ 6. Manejo de contaminantes } & 6 & Tratamiento de aguas residuales \\
\hline & 7 & Emisión excesiva de gases tóxicos \\
\hline 7. Infraestructura urbana & 8 & Congestionamiento vehicular \\
\hline \multirow{2}{*}{ 8. Inclusión social - Desigualdades } & 9 & Escolaridad promedio \\
\hline & 10 & Participación laboral femenina \\
\hline \multirow{3}{*}{ 9. Salud } & 11 & Tasa de mortalidad infantil de menores de 5 años \\
\hline & 12 & Población en el AMSS sin acceso a seguros médicos \\
\hline & 13 & Vacunación \\
\hline 10. Área verde & 14 & $\%$ de área verde urbana \\
\hline \multirow{2}{*}{ 11. Educación y cultura } & 15 & Infraestructura educativa deficiente \\
\hline & 16 & Museos, galerías y escuelas de bellas artes \\
\hline
\end{tabular}

Fuente: elaboración propia.

\section{Evaluación de indicadores}

La metodología para evaluación de los indicadores en este modelo es del tipo multidimensional debido a que los indicadores tienen naturalezas distintas. Esta fase inicial del proyecto de investigación es eminentemente diagnóstica y concluye con el perfil de una serie de indicadores que describen el grado de sostenibilidad del desarrollo urbano en el AMSS obtenido con cifras oficiales publicadas entre el año 2014 y el año 2018. Anteriormente se anunció que los indicadores seleccionados serían los que se pudieran medir desde la UFG, en el tiempo asignado para esta primera fase y con los recursos reales disponibles para el proyecto. En futuras fases, la presentación del sistema general de evaluación, idealmente, deberá seguir un protocolo similar, definido y se mantendrá uniforme en la medida de lo posible.

\section{Resultados}

El proceso de análisis y evaluación de esta fase inicial de la medición del grado de sostenibilidad del desarrollo urbano se concreta a continuación, en la Tabla 7, sumando los resultados obtenidos para cada indicador y luego obteniendo un índice 
(promedio) que califica el grado de sostenibilidad en el Área Metropolitana de San Salvador.

La Tabla 7, al mismo tiempo, es el resultado del cumplimiento de los cuatro (4) objetivos específicos de este documento:

- Identificar indicadores en modelos de desarrollo urbano, aplicables a este estudio y relacionarlos con las causales de la problemática de los sistemas urbanísticos del AMSS.

- Identificar indicadores de Observatorios de la Sostenibilidad en España y relacionarlos con las causales de la problemática de los sistemas urbanísticos del AMSS.

- Elaborar un sistema de evaluación para los indicadores propuestos.

- Estructurar un modelo de desarrollo urbano que mida el grado de sostenibilidad en el AMSS.

\section{Conclusiones}

La primera conclusión es que entre las soluciones metropolitanas que deben ser implementadas en el AMSS para lograr un cambio hacia el desarrollo

\section{Tabla 7}

\section{Modelo de sostenibilidad UFG}

\begin{tabular}{l|c}
\hline Modelo de Sostenibilidad UFG & 17 \\
\hline 1. Déficit de vivienda & 38 \\
\hline 2. Tasa de desempleo de mujeres y hombres de todas las edades & 6.3 \\
\hline 3. PIB per cápita en relación con el PIB en países desarrollados & 8.3 \\
\hline 4. Servicios del Estado no accesibles a través de Internet & 42 \\
\hline 5. Número de hogares sin acceso a Internet & 51 \\
\hline 6. Tratamiento de aguas residuales & 44 \\
\hline 7. Emisión excesiva de gases tóxicos & 38 \\
\hline 8. Congestionamiento vehicular & 43 \\
\hline 9. Escolaridad promedio & 46 \\
\hline 10. Participación laboral femenina & 0 \\
\hline 11. Tasa de mortalidad infantil de menores de 5 años & 68 \\
\hline 12. Población en el AMSS sin acceso a seguros médicos & 83 \\
\hline 13. Vacunación & 9.5 \\
\hline 14. Porcentaje de área verde urbana & 69 \\
\hline 15. Infraestructura educativa deficiente & 25 \\
\hline 16. Museos, galerías y escuelas de bellas artes & $\mathbf{5 8 8}$ \\
\hline Total & $\mathbf{3 7}$ \\
\hline Índice (promedio) & . \\
\hline
\end{tabular}

Fuente: elaboración propia. 
la primera es la voluntad del Estado y de todos los ciudadanos de erradicar la pobreza. Ya se vio que los Estados miembros de las Naciones Unidas reconocieron que "el mayor desafío del mundo actual para lograr el desarrollo sostenible es la erradicación de la pobreza" (ONU, 2015).

Segunda conclusión. Para encaminar este país hacia el desarrollo sustentable es culturizar a la población, debe entenderse que la cultura (valores, educación y respeto) es esencial en cualquier sociedad para desarrollarse con dignidad. Debe diferenciarse entre formación académica y educación, el conocimiento (académico) es una cosa, los valores y el respeto (educación) son otra.

Tercera conclusión. Muchos ciudadanos del AMSS parecen nacer y crecer en un AMSS como si el crecimiento y tolerancia al deterioro de la ciudad fueran ilimitados. Esta idiosincrasia evidencia cierta especie de paradigma de producción o explotación ilimitada de recursos en un país extremadamente pequeño y no se percatan de que consumen "N" veces más de su capacidad de producción, lo grave de la situación es que el país no cuenta con una política ambiental clara y eficaz que asegure la reposición y conservación de los recursos naturales que día a día se van extinguiendo.

Cuarta conclusión. La mala planificación y control del desarrollo urbano se perciben a simple vista en el AMSS, la ausencia de memoria histórica se experimenta en diversos sectores de la ciudad y las soluciones para resolver esos problemas cada vez son más complicadas y costosas.

Quinta conclusión. Los servicios urbanos, nos referimos a los de todos los días, a los sistemas que proporcionan agua, alimentos, energía, gestión de residuos, así como transporte público y de carga que demandan una gran cantidad de recursos y a menudo requieren una infraestructura costosa, por lo que el desarrollo urbano del AMSS debe ser controlado.

Sexta conclusión. Es importante iniciar una campaña de concientización masiva para todos los ciudadanos que contaminamos, destruimos, deterioramos, que no cuidamos, ni apreciamos lo que tenemos...

Séptima conclusión. Las consecuencias de la normativa actual para proyectos de alta densidad son urbanizaciones con alto grado de hacinamiento, bajísimos estándares de construcción, insuficiencia de áreas verdes, absolutamente antiestéticas y entre otras cosas peligrosas porque propician la inseguridad y la descomposición social, por lo que se debe revisar la normativa en los reglamentos de diseño y construcción.

Octava conclusión. Las interrogantes del prefacio que motivaron el desarrollo de esta investigación son:

¿Estamos creciendo o decreciendo?

¿Hacia dónde vamos?

¿Qué queremos ser?

¿Vamos realmente en la dirección que queremos?

¿Con qué herramientas tecnológicas, ecológicas y sociales contamos para diseñar, controlar y orientar el desarrollo del AMSS hacia un futuro ideal? 
¿Qué soluciones metropolitanas necesitan ser implementadas en el AMSS para lograr un cambio hacia el desarrollo?

¿Cómo crear un AMSS más próspera para todos los ciudadanos?

¿Cuáles pueden ser las consecuencias de la urbanización no controlada en el AMSS?

¿Cómo puede el AMSS volverse un área sustentable y próspera?

El documento responde estas preguntas de manera superficial y se ha perfilado efectuando una selección y evaluación de indicadores que describen la situación actual del desarrollo urbano en el AMSS utilizando, en su mayoría, cifras estatales publicadas entre 2014 y 2018.

Novena conclusión. Cultura ciudadana quiere decir vida urbana, calidad de vida y al mismo tiempo es una condición esencial para que las ciudades alcancen la sostenibilidad. Este tema podría enfocarse por un lado en como la vida urbana sin educación es causa de muchos problemas y nuestro país es un reflejo de eso y por otro en los factores inadecuados de la normativa vigente que ha dado como resultado "soluciones" habitables poco dignas.

Conclusión final. En el modelo de evaluación planteado, el índice máximo posible es $\mathbf{1 0 0}$, el índice resultante que se ha detectado con la medición de los indicadores adoptados es $\mathbf{3 7}$. Este índice es un valor que confirma la hipótesis tácita en las preguntas del prefacio, es un valor que debería alertar a la comunidad en general y en consecuencia tratar de implementar acciones urbanísticas correctivas y preventivas en el corto y mediano plazo. Es posible y también probable... que, si se siguen incorporando indicadores a este Modelo de Sostenibilidad el índice tiende a disminuir, y ésta es precisamente la justificación de la creación de un Laboratorio Urbano Institucional, para incorporar nuevos indicadores al modelo con el objeto de monitorear el efecto de la planificación urbana de las dos últimas décadas del siglo XXI en el AMSS.

El modelo planteado en este estudio debe entenderse como un prototipo que sienta las bases para la creación de este Laboratorio Urbano (Observatorio de la Sostenibilidad del Desarrollo Urbano) de forma tal que semestral o anualmente pueden publicarse y agregarse indicadores a los objetivos estratégicos para profundizar en el sistema de evaluación de la sostenibilidad del desarrollo urbanístico del AMSS.

El estudio deja abierta la serie de preguntas incluidas en el Prefacio cuyas respuestas prácticamente se convierten en futuros temas de investigación, algunos más profundos que otros, todas las preguntas requieren respuestas a la brevedad posible y todas son esenciales...

En cuanto a la profundidad de los temas, esta dependerá siempre de los recursos y tiempos asignados a cada fase de la investigación, pero para facilitar al estudioso interesado la identificación de dichos temas se mencionan a continuación algunas preguntas que inducen a hipótesis en cada caso: ¿Hacia dónde vamos? A muchos sectores de la sociedad parece no importarles esta interrogante... ¿Qué queremos ser? En general no parece existir una conciencia 
clara sobre lo que los ciudadanos del AMSS aspiran a ser... ¿Vamos realmente en la dirección que queremos? Por la realidad que se vive a diario se presume que muchos ciudadanos no se preocupan por la dirección que lleva el desarrollo urbano en el AMSS... y finalmente, ¿tiene San Salvador realmente la posibilidad de convertirse algún día en una ciudad inteligente?

\section{Recomendaciones}

La planificación urbana es un aspecto clave para lograr el desarrollo sostenible y por ende una sociedad próspera. Es urgente, esencial, vital, acelerar la búsqueda de soluciones sostenibles y efectivas en el ambiente construido y natural del AMSS, algunas recomendaciones para ello son:

- Debemos aprender de los enfoques positivos y acertados del mundo desarrollado, y de los errores también.

- Se deben identificar e implementar soluciones viables para nuestro país y tratar de controlar los efectos nocivos de la urbanización masiva.

- Si se quiere crear un AMSS más próspera para todos los ciudadanos hay que determinar las diversas influencias existentes entre el Área Metropolitana y sus entornos inmediatos, asimismo los flujos de circulación y procesos logísticos deben optimizarse en forma circular.

- Debe educarse a la población inculcándole el concepto del "respeto" por el medio ambiente, por sus conciudadanos, por sí mismos y por el derecho ajeno. Una herramienta eficaz para iniciar el cambio podrían ser campañas de concientización locales.
- Planificar y controlar el desarrollo urbano del AMSS enfocados hacia un futuro sostenible creando e implementando herramientas tecnológicas, ecológicas y sociales.

- Cultura ciudadana quiere decir vida urbana, calidad de vida y al mismo tiempo una condición importante para que las ciudades alcancen la sostenibilidad. Este tema podría enfocarse, por un lado, en cómo la vida urbana con un mínimo de formación académica, pero sin educación..., es causa de muchos problemas y por otro, en los factores obsoletos de la normativa vigente.

- En lo referente a la planificación adecuada de áreas verdes, se debe hacer una revisión de la normativa de OPAMSS, las urbanizaciones de alta densidad son las que deberían contar con mayores porcentajes de área verde puesto que la cantidad de usuarios que la necesitan es mucho mayor que la cantidad de usuarios de urbanizaciones de baja densidad.

- En relación con el tema de la educación, no se debe confundir educación con formación, ya anotamos al inicio del documento que una gran parte del $60 \%$ de la población del país ha logrado cursar hasta $9^{\circ}$ grado, pero que su nivel de educación es "paupérrimo“. Hay que promover la educación, el respeto y la cultura en nuestro país.

- Los desafíos para lograr el cambio deben identificarse con absoluta claridad y se debe planificar cómo abordarlos. Este tema implica un análisis cuidadoso de la morfología urbana (configuración de la ciudad) para tratar de identificar los puntos o factores que impiden la auto sostenibilidad. 


\section{Referencias bibliográficas}

Alcaldía de San Salvador. Trámites en los distritos de San Salvador. Recuperado de: https:// alcaldiass.wordpress.com/2010/02/12/estasson-las-direcciones-de-nuestros-distritos/. (fecha de consulta el 26 de enero de 2019)

Asamblea Legislativa de El Salvador. (1983). Constitución de la República de El Salvador. Art. 119. Recuperado de: http://pdba.georgetown. edu/Constitutions/ElSal/constitucion.pdf (fecha de consulta el 20 de junio de 2019)

Asamblea Legislativa. (1993). Decreto No. 432. Recuperado de: https://www.asamblea. gob.sv/sites/default/files/documents/decretos/171117_072934147_archivo_documento_ legislativo.pdf (fecha de consulta el 10 de junio de 2019)

Ayuntamiento de Barcelona. (2010). La cultura es el cuarto pilar del desarrollo sostenible. Barcelona, España.

BID. (2016). Guía metodológica - Ciudades emergentes y sostenibles. Tercera edición. Autor.

BID. (2019). Cómo medir la sostenibilidad urbana, un vecindario a la vez. Recuperado de: https://blogs. iadb.org/ciudades-sostenibles/es/sostenibilidadurbana/ (fecha de consulta el 3 de abril de 2019)

Bouskela, M., Casseb M., Bassi, S., De Luca, C. y Facchina, M. (2016). La ruta hacia las Smart Cities: Migrando de una gestión tradicional a la ciudad inteligente. BID. Recuperado de: https:// books.google.com.sv/books/about/La_ruta_hacia_las_smart_cities.html?id=TdB3DwAAQ-
BAJ\&printsec=frontcover\&source $=$ kp_read button\&redir_esc $=\mathrm{y} \# \mathrm{v}=$ onepage\&q\&f=false

CAMBRABCN.ORG. (2019). Informe sobre Barcelona en el mundo, en 30 indicadores clave. Recuperado de: https://www.cambrabcn.org/ es/servicios-corporativos/estudios/observatoriode-barcelona-

Carcache, C. (2019). Sostenibilidad del desarrollo urbano del AMSS. P29.

Carrión, F. y Hanley, L. (2005). Revitalización Urbana: Metodologias de evaluación e impactos esperados. FLACSO. Quito, Ecuador. Recuperado de: https://blogs.iadb.org/ciudades-sostenibles/ es/gentrificacion-en-numeros/

Carta de Aalborg. (1994). Conferencia Europea sobre Ciudades Sostenibles. Dinamarca. Recuperado de: http://www.ecourbano.es/imag/ REF\%20CARTA\%20DE\%20AALBORG.pdf

Carta de Leipzig. (2007). Ciudades europeas sostenibles. Recuperado de: https://www. fomento.gob.es/portal-del-suelo-y-politicasurbanas/otros-proyectos-y-actividades/agendaurbana-europea/la-carta-de-leipzig-2007sobre-ciudades-europeas-sostenibles (fecha de consulta el 30 de abril de 2019)

Carta de Málaga. (2011). Ciudades socias del proyecto CAT-MED. Recuperado de: http:// www.catmed.eu/pag/es/11/la-carta-de-malaga. (fecha de consulta el 30 de abril de 2019)

Castro Bonaño, M. (2002). Indicadores de desarrollo sostenible urbano. Una aplicación para Andalucía. España: Universidad de Málaga. 
CAT-MED. (2019). Servicio de Programas Europeos Ayuntamiento de Málaga. Metodología de trabajo y resultados, España. Recuperado de: http://www.catmed.eu/pag/es/10/el-modelourbano (fecha de consulta el 2 de abril de 2019)

CEDEUS. (2019). Nueve metros cuadrados por habitante. Universidad Católica de Chile. Recuperado de: https://www.cedeus.cl/nuevemetros-cuadrados-por-habitante/, (Fecha de consulta el 8 de agosto de 2019)

CGLU. (2010). Cultura, cuarto pilar del desarrollo sostenible. Culture 21. Recuperado de: http:// www.agenda21 culture.net/es/documentos/ cultura-cuarto-pilar-del-desarrollo-sostenible (fecha de consulta el 16 de enero de 2019)

COAMSS-OPAMSS. (2015). Plan estratégico 2016-2020. E1 Salvador: Autor.

COAMSS-OPAMSS. (2010). Política de Espacios Públicos. Recuperado de: file://C:/ Users/ccarcache/Downloads/Politica_de_ Espacios_Publicos.pdf (fecha de consulta el 11 de junio de 2019)

CONASAV. (2018). Plan El Salvador Sustentable. San Salvador: Autor. Recuperado de: http://www.marn.gob.sv/conasav-prioriza-ejesestrategicos-de-plan-el-salvador-sustentable/ (Fecha de consulta el 21 de febrero de 2019)

Datosmacro.com.(2017).Población de El Salvador 2017- La población en El Salvador aumenta. Recuperado de: https://datosmacro.expansion. com/demografia/poblacion/el-salvador. (fecha de consulta el 19 de febrero de 2019)
Datosmacro.com. (2019). Cantabria 2019. Recuperado de: https://datosmacro.expansion. com/ccaa/cantabria (fecha de consulta el 15 de abril de 2019)

De la Roca, Navarrete, y Larraín. (2005). Urban Revitalization: Assessment Methodologies and Expected Impacts. Interamerican Development Bank. Recuperado de: http://www.iadb.org

Diario Oficial. (2008). Tomo 380. Perfil epidemiológico. Recuperado de: http://new. paho.org/hq/dmdocuments/2010/Politicas_ Nacionales_Salud-E1_Salvador-2008.pdf (fecha de consulta el 5 de junio de 2019)

DIGESTYC. (2007). Censo de población y vivienda. San Salvador: Autor.

DIGESTYC. (2014). Encuesta de hogares de propósitos múltiples. San Salvador: Autor.

DIGESTYC. (2015). El Salvador: Estimaciones y Proyecciones de Población. San Salvador: Autor. Recuperado de: http://www.digestyc.gob.sv/ index.php/novedades/avisos/540-el-salvadorestimaciones-y-proyecciones-de-poblacion.html (fecha de consulta el 27 de marzo)

DIGESTYC. (2016). Encuesta de hogares de propósitos múltiples. San Salvador: $\mathrm{Au}-$ tor. Recuperado de: https://www.google.com/ search?q=encuesta + de + hogares $+d e+$ prop $\%$ C3\%B3sitos + m\%C3\%BAltiples+2016+incae\&rlz=1C1GCEA_enSV837SV837\&o$\mathrm{q}=$ encuesta $+\mathrm{de}+\& \mathrm{aqs}=$ chrome $.1 .69 \mathrm{i} 57 \mathrm{j} 35 \mathrm{i}-$ 39j014.5279j0j9\&sourceid $=$ chrome $\&$ ie $=U T F-8$ (fecha de consulta el 24 de mayo de 2019) 
DIGESTYC. (2017). Encuesta de hogares de propósitos múltiples. San Salvador: $\mathrm{Au}-$ tor. Recuperado de: https://www.google.com/ search?q=encuesta $+\mathrm{de}+$ hogares $+\mathrm{de}+$ prop $\%-$ C3\%B3sitos $+\mathrm{m} \% \mathrm{C} 3 \%$ BAltiples+2016+incae\&rlz=1C1GCEA_enSV837SV837\&o$\mathrm{q}=$ encuesta $+\mathrm{de}+\& \mathrm{aqs}=\mathrm{chrome} .1 .69 \mathrm{i} 57 \mathrm{j} 35 \mathrm{i}-$ 39j014.5279j0j9\&sourceid $=$ chrome\&ie $=U T F-8$ (fecha de consulta el 24 de mayo de 2019)

ECODISTRICTS. (2019). Vecindarios para todos. Recuperado de: https://ecodistricts.org/ (fecha de consulta el 8 de abril de 2019)

elmundo.sv. (2018). Parque de motocicletas creció un $50 \%$ en tres años. Recuperado de: https:// elmundo.sv/parque-de-motocicletas-crecio-un50-en-tres-anos/ (fecha de consulta el 8 de junio de 2019)

Erazo, F. (2019). Ecoparque El Espino: reserva forestal. Recuperado de: http://archivo. archivoscp.net $/$ index 2 .php? option $=\mathrm{com}_{-}$ content\&do_pdf=1\&id=688 (fecha de consulta el 10 de junio de 2019)

Espinosa, D. (2018). Indice de desempeño ambiental. Calificación del mundo en desarrollo sostenible en el 2018. Costa Rica: FUNDAPEM. Recuperado de: https://pensandodesdecentroamerica.wordpress. com/2018/02/21/indice-de-desempenoambiental-calificacion-del-mundo-en-desarrollosostenible-en-el-2018/ (fecha de consulta el 5 de abril de 2019)

EUROPAPRESS. (2010). Valladolid cuenta con más museos por habitante que ciudades como Madrid, Barcelona, Sevilla o Valencia. Recuperado de https://www.europapress.es/castilla-y- leon/noticia-valladolid-cuenta-mas-museoshabitante-ciudades-madrid-barcelona-sevillavalencia-20100517163343.html (fecha de consulta el 11 de junio de 2019)

Fernández, C. (2007). Indicadores de sostenibilidad local de Cantabria: Resumen del proceso de elaboración. Recuperado de: http:// www.medioambientecantabria.es/documentos_ contenidos/21748_5.4.pdf (fecha de consulta el 2 de mayo de 2019)

Ferrufino, C. (2008). VIOLENCIA, DESARROLLO URBANO Y ESPACIO PÚBLICO. Recuperado de: http://cef.uca. edu.sv/doe/images/QUE\%20HACEMOS/ publicaciones/QH_P_A/articulo\%20ferrufino. pdf (fecha de consulta el 11 de junio de 2109) Foro-ciudad.com. (2018). Población de Santander. Recuperado de: https://www.foro-ciudad.com/ cantabria/santander/habitantes.html\#Evolucion (fecha de consulta el 16 de abril de 2019)

Fundación Mi Parque. (2012). La gran diferencia de $m 2$ de áreas verde por persona en Latinoamérica. Recuperado de: https://www.miparque.cl/lagran-diferencia-de-m2-de-areas-verde-porpersona-en-latinoamerica/

FUNDASAL. (2012). Propuesta de Ley Especial de Vivienda de Interés Social. Recuperado de: file:///C:/Users/ccarcache/Documents/ investigación $\% 20$ sostenibilidad/indicadores $\% 20$ U F G / L e y \% 20 d e \% 20 vivi en d a \% 20 FUNDASAL.pdf

Grande, C. (2011). Modernización del sistema de transporte masivo en el AMSS. Barcelona: Fundación Politécnica de Catalunya. 
Guevara, P. y Arce, R. (2016). Estado de la vivienda en Centroamérica. Recuperado de: http://x.incae.edu/ES/clacds/publicaciones/pdf/ Estado_de_la_Vivienda_en_CA.pdf

IADB. (2016). Programa Ciudades Emergentes y Sostenibles - CES. Recuperado de: https:// www.iadb.org/es/desarrollo-urbano-y-vivienda/ programa-ciudades-emergentes-y-sostenibles (fecha de consulta el 9 de mayo de 2019)

IAIP. (2017). Indicadores de servicios del Estado accesibles a través de Internet. Recuperado de: https://www.transparencia.gob.sv/system/ institutions/rating_reports/000/000/011/ original/MDN.pdf?1521584688. El Salvador: Autor.

Internet World Stats. (2017). Penetración de Internet en Centroamérica. Recuperado de: https://www.elsalvador.com/noticias/ negocios/el-salvador-es-el-tercerpais-con-penetracion-de-internet-encentroamerica/542187/2018/ (fecha de consulta el 3 de junio de 2019)

La Prensa Gráfica. (2015). Principales calles de AMSS en nivel crítico de tráfico. Recuperado de: https://www.laprensagrafica.com/elsalvador/ Principales-calles-de-AMSS-en-nivel-criticode-trafico-20151227-0028.html (fecha de consulta el 5 de junio de 2019)

LaPrensa Gráfica.(2017).Tráficovehicularexcede capacidades y medidas del VMT. Recuperado de: https://www.laprensagrafica.com/elsalvador/ Trafico-vehicular-excede-capacidades-ymedidas-del-VMT-20170205-0044.html (fecha de consulta el 5 de junio de 2019)
La Prensa Gráfica. (2017). Casi medio millón de vehiculos en el AMSS. Recuperado de: https://www.laprensagrafica.com/elsalvador/ Casi-medio-millon-de-vehiculos-en-elAMSS-20170611-0049.html (fecha de consulta el 5 de junio de 2019)

Luciani, A. (2016). Los espacios verdes no llegan al minimo fijado por la OMS. PRESSREADER. Recuperado de: https://www.pressreader.com/ (Fecha de consulta el 8 de agosto de 2019)

Marmolejo, C., Chica, J.E., y Moix, M. (2011). Estructura urbana y policentrismo: Un análisis de los sistemas urbanos a partir de las relaciones económicas en la región metropolitana de Barcelona. ACE: Architecture, City and Environment $=$ Arquitectura, Ciudad y Entorno [en línea]. 2011, Año 6, núm. 18, febrero. P. 265-296

MARN. (2013). Visión estratégica 2010-2014. Recuperado de http://www.marn.gob.sv/visionestrategica-2010-2014-y-acciones-iniciales/

MARN. (2014). Visión Estratégica 2010-2014 y Acciones Iniciales. Recuperado de: http://www. marn.gob.sv/vision-estrategica-2010-2014-yacciones-iniciales/ (fecha de consulta el 25 de enero de 2019)

MARN. (2013). Estrategia Nacional de Saneamiento Ambiental. Recuperado de: http:// www.marn.gob.sv/estrategia-nacional-desaneamiento-ambiental/

MARN. (2016). Estrategia Nacional de Saneamiento Ambiental. Recuperado de: http:// www.marn.gob.sv/estrategia-nacional-desaneamiento-ambiental/ 
Ministerio de Fomento. (2018). Carta de Leipzig. España. Recuperado de: https://www.fomento. es/areas-de-actividad/arquitectura-vivienday-suelo/urbanismo-y-politica-de-suelo/ investigacion-sobre-temas-urbanos/proyectourban-net/publicaciones/carta-de-leipzigsobre-ciudades-europeas-sostenibles

Ministerio de Salud. (2018). Indicadores del sistema nacional de salud, año 2013-2017. Recuperado de: https://www.salud.gob.sv/archivos/DVS/ uniec/boletines_indicadores_SNS/Boletin_ de_indicadores_del_Sistema_Nacional_de_ Salud_2017-2018.pdf (fecha de consulta el 13 de junio de 2019) Parcialmente modificada.

Miranda, K. (2005) Hacia un sistema de espacios verdes para el Área Metropolitana de San Salvador. Tesis para optar al título de Magíster en Asentamientos Humanos y Medio Ambiente. Santiago de Chile.

Miranda, K. y De la O. (2014). The major council and the planning office for Metropolitan Area of San Salvador, as a model for urban management. Lincoln Institute of Land Policy.

Navarro, S. (2008). Análisis del flujo vebicular. Recuperado de: https://sjnavarro.files.wordpress. com/2008/08/analisis-de-flujo-vehicular-cal-ymayor.pdf (fecha de consulta el 5 de junio de 2019)

Nogués, S. y Salas, H. (2009). Modelos de crecimiento urbano. Estrategias de planificación $y$ sostenibilidad en Cantabria. Universidad de Cantabria. Recuperado de: https://upcommons. upc.edu/bitstream/handle/2099/11341/01_ PROCEEDINGS_M1_02_0007.pdf (fecha de consulta el 9 de abril)
OAMU. (2012). CAT MED Modelos Urbanos Sostenibles. Málaga, España: Autor.

Observatorio Barcelona. Informe Barcelona. Recuperado de: https://www.cambrabcn.org/es (fecha de consulta el 7 de mayo de 2019)

Observatorio de la Sostenibilidad de Asturias. (2017). Red ambiental de Asturias. Recuperado de: https://www.asturias.es/portal/ site/medioambiente/menuitem.5b317acdad06f934ead5ba10a6108a0c/?vgnextoid $=4 \mathrm{e} 8 \mathrm{~cd}-$ 77bacc1c110VgnVCM1000006a01a8c0RCRD\&i18n.http.lang=es (fecha de consulta el 4 de mayo de 2019)

Observatorio de vivienda. (2011). Sistema Estatal de Información e Indicadores de Suelo y Vivienda. Guanajuato, México. Recuperado de: file:///C:/ Users/ccarcache/Documents/investigación\%20 sostenibilidad/índices\%20-\%20escalas\%20 matriciales/Sistema_indicadores\%20de\%20 vivienda.pdf.

OIT-CINTERFOR. (2013). ¿QQué son y cómo se construyen los indicadores en la evaluación de impacto? Recuperado de: http://guia.oitcinterfor. org/como-evaluar/como-se-construyen-indicadores (fecha de consulta el 5 de febrero de 2019)

ONU. (2013). Agenda 2030 y los Objetivos de Desarrollo Sostenible. Recuperado de http://www. marn.gob.sv/vision-estrategica-2010-2014-yacciones-iniciales/

ONU. (2015). La Asamblea General adopta la Agenda 2030 para el Desarrollo Sostenible. https://www.un.org/sustainabledevelopment/ es/2015/09/la-asamblea-general-adopta-la- 
agenda-2030-para-el-desarrollo-sostenible/ (fecha de consulta el 25 de mayo de 2019)

ONU. (2015). Objetivos de desarrollo del milenio. P5. Recuperado de: https://www.un.org/es/ millenniumgoals/pdf/2015/mdg-report-2015_ spanish.pdf(fecha de consulta el 7 de junio de 2019)

ONU.(2017).https://blogs.un.org/es/2017/02/24/ los-pilares-de-la-onu-desarrollo-si-perosostenible-2/ (fecha de consulta el 21 de enero de 2019)

OPAMSS. (2014). Plan municipal de ordenamiento territorial. San Salvador: Autor.

OPS. (2019). El Salvador recibe apoyo de OPS/OMS para Reducir la Mortalidad Infantil. Recuperado de: https://www. paho.org/els/index.php?option =com content\&view=article\&id=112:el-salvadorrecibe-apoyo-ops-oms-reducir-mortalidadinfantil\&Itemid=291 (fecha de consulta el 6 de junio de 2019)

OSCCP.(2008). Estrategia del desarrollo sostenible del Principado de Asturias. España: Autor.

Peñate, S. (2018). Ministerio reconoce que falta más inversión en infraestructura escolar. Recuperado de: https://www.laprensagrafica.com/elsalvador/ Ministerio-reconoce-que-falta-mas-inversionen-infraestructura-escolar-20180316-0094.html (fecha de consulta el 10 de junio de 2019)
Quiroga M., R. (2007). Indicadores ambientales y de desarrollo sostenible: avances y perspectivas para América Latina y el Caribe. CEPAL. Chile.

Rodríguez, A.y Sugranyes, A. (2004). El problema de vivienda de los "con techo". Revista EURE (vol. 30, N91), PP.53-65, Santiago de Chile.

SIVS. (2015). Presupuesto de vivienda. Recuperado de: http://viviendasocial.vivienda. gob.sv/www/costos/wf_costos.aspx

Viceministerio de Vivienda y Desarrollo Urbano. (2015). Política nacional de vivienda y hábitat de El Salvador. San Salvador: Autor.

Viceministerio de Vivienda y Desarrollo Urbano. (2018). Solicitud de información No. 062-2018. San Salvador: Autor.

Yale University. (2018). Índice de desempeño Ambiental. Recuperado de: epi.yale.edu 